\title{
Engaging Diverse Secondary Students in International Collaborative Networked Learning
}

\author{
C. Candace Chou \\ University of St. Thomas \\ Chi-Syan Lin \\ National University of Tainan, Taiwan \\ Mark van 't Hooft \\ Kent State University \\ Yi-Mei Lin \\ National Chung Cheng University, Taiwan
}

\begin{abstract}
This study examines the processes of engaging a group of highly diverse $7^{\text {th }}$ and $8^{\text {th }}$ grade students in the utilization of information and communication technology (ICT) for collaborative activities through a global networked learning environment called APEC Cyber Academy. Thirtysix middle school students went through a nine-week project-based learning program that aimed at improving ICT skills and promoting international peer learning. Although students showed strong interest in learning about ICT, the findings suggest that students need to be coached in collaboration skills, given appropriate roles to ensure proper division of labor, and supervised closely to ensure the completion of tasks.
\end{abstract}

Keywords: motivation, international networked learning, ICT, APEC Cyber Academy

\section{Introduction}

Today's young learners, the Net-generation, are growing up with digital media all around them. The N-Geners work, learn, and play with computers, video games, cell phones, DVDs, and other digital media (Tapscott, 1999). The Internet has also become an important tool for learning and socializing. Research has shown that $70 \%$ of young learners (14-18 years old) spend one hour a day online and $60 \%$ view Internet information as more useful than print (Teen Research Unlimited, 1999). The Pew Internet Project 2007 report has indicated that $55 \%$ of online teens ages $12-17$ have created a profile on a social networking site such as Facebook or MySpace. Seven in ten $(70 \%)$ teens who use social networking also read blogs by others. Three in four $(76 \%)$ teens who have a social networking ites have posted comments to a friend's blog (Lenhart et al., 2007). However, parents and teachers as digital aliens and immigrants are falling behind in understanding why and how the N-Geners use the digital technology (Prensky, 2001). To bridge the gap between educators and young learners in the use of information and communication technology, it is important to understand how to take advantage of the affordances of digital tools that the N-Geners 
are familiar with to engage them in learning. As educators plan technology-based or Webbased activities for school-aged learners, it is essential to devise activities that will engage them in learning and self-discovery. Thus, the objectives of this study are to examine student perceptions toward networked learning and what motivates students to use digital tools for learning projects in the first place.

\section{Literature Review}

Research has shown that technology can bridge the achievement gap (Au, 2006) and engage students in learning (Gambrell \& Morrow, 1996; Valdez, 2001). Gambrell (2006) stipulates three ways in which technology can foster reading engagement: (1) access to reading materials, (2) opportunities for selfselection, and (3) social interactions about text. First, the Internet provides easy access to materials that would not be available within a few mouse clicks compared to print. Therefore, technology has increased student access to digital texts that may enhance their reading interest. Second, students have more choices in topics, graphics, and types of resources through the Internet. Freedom of choice is linked to motivation in the classroom (Gambrell \& Morrow, 1996). Students who are allowed to choose their own reading texts tend to put forward more effort into learning and understanding the materials (Schiefele, 1991). Third, motivation theories have emphasized that learning can be facilitated through social interaction with others. Sharing ideas and exchanging views with others about world events, books, neighborhoods, or other common interests are important to keep learners engaged. The popularity of social networking sites such as MySpace or Facebook among students and young adults indicates that students want to be heard and learn what others think. Internet technologies provide a perfect venue for such social interaction.
Collaborative networked learning can encourage conversation (Jenlink \& Carr, 1996), reflection, idea sharing, interaction, knowledge construction (Scardamalia \& Bereiter, 1996), and community building (Pea, 1993). Studies from both education and computer science have indicated positive learning outcomes resulting from computer-based collaborative learning (Collis, 1994; Henri \& Rigault, 1996; Kaye, 1992). Collaborative networked learning technologies can provide support for learner interaction and learning. For example, online libraries make information retrieval easily accessible; online bulletin boards promote equal participation by encouraging the participation of shy students who would never speak up in traditional classroom; chat rooms allow students to work in either public or private space; and audio/video conferencing permits students to see and hear each other without driving afar to the campus. As described by Verdejo (1996), two separate but interrelated spaces are important for online cooperative learning, "the shared object space where actions take place and the conversation space where interactions are carried out" (p. 85). The intersection between task-oriented action and social-emotional-oriented conversation can contribute to learning in an online environment.

Interaction is considered an important key to knowledge construction in computersupported learning (Gunawardena \& Zittle, 1997). Most of the research have focused on the support of social interaction that promotes cognitive learning and less on the support of social interaction that aims at social-emotional processes to strengthen group dynamics (Kreijns, Kirschner, Jochems, \& Buuren, 2007). In face-to-face environments, learning take place in both formal settings such as the classroom and informal settings such as small talks next to the water cooler at work place. In 
networked learning, students are engaged in both formal discussions in the bulletin boards and informal discussions in the chat rooms. Kreijns, Kirschner, Jocherns, and Buuren (2007) postulated that a sociable computer-supported collaborative learning (CSCL) environment can fulfill both the learning and social needs of students. A sociable CSCL environment refers to "CSCL environments with both educational functionality and social functionality" (p. 178, Kreijns, Kirschner, Jochems, \& Buuren, 2007). Sociable CSCL environment can enable socioemotional processes such as interpersonal relationship development, community building, and enhanced trust which are all major factors in building effective collaboration in networked learning. Most of the research that had been performed in this area used university students as sample populations. This study will explore if the same propositions on motivation and learning can be supported in $\mathrm{K}-12$ settings.

\section{Background}

APEC Cyber Academy (ACA, http:// linc.hinet.net/apec/) is designed specifically to provide student-centered learning opportunities for enhancing skills in information and communication technologies (ICT), team collaboration, and international friendship among K-12 students and teachers around the world. ACA is currently hosted by the APEC Digital Content Production Center (APEC CPC) under the auspices of APEC/ EDNET and the Ministry of Education of Chinese Taipei (Taiwan). ACA is a secured Web site and the access requires a login ID and password. ACA was approved by the Department of Education and compliant with the Child Online Protection Act (COPA) that was enacted by U.S. Congress. Parent consent forms from all students are required prior to the beginning of the ACA project.
The three motivation factors that mentioned by Gambrell (2006) were well-reflected in the design of the APEC Cyber Academy. For the first factor on access to reading materials, all materials are created by students and stored on the server so the content is well-maintained. Access is not a problem for participating students. For the second factor on opportunities for self-selection, participants have the choice to work on a project in the appropriate grade level. Students have to search the Internet to select information for the design of their projects. They collaboratively create the content and present the project to their peers. Finally, for the third factor on social interaction, the forum, chat, and mailbox functions are available for learners to connect with each other for information gathering, project sharing, and other social purposes. Students conduct peer-evaluations to provide feedback for each other.

ACA hosts an annual, international, online contest. In this contest, students are engaged in project-based learning that requires the following ICT skills: Internet research, Web page construction, digital video and graphics production, and proper online communication. These projects are described in Table 1 (Lin, Chou, \& Bagley, 2007). K-12 Teachers of the APEC countries (including Australia, Brunei Darussalam, Canada, Chile, People's Republic of China, Hong Kong, China, Indonesia, Japan, Republic of Korea, Malaysia, Mexico, New Zealand, Papua New Guinea, Peru, Philippines, Russia, Singapore, Chinese Taipei, Thailand, United States, and Vietnam) are encouraged to register teams of students that the teachers can provide learning support to participate in the international contest. Each team can participate in one of the projects listed in Table 1. Each project runs for nine weeks. Specific activities are planned for each week. Students in the same team from the same school follow the weekly activity guidelines to collaborate on 
projects and upload artifacts (e.g., Web pages) to the ACA Web site for peer evaluation. All registered participants can provide peer evaluation on any given team from any country. Through peer evaluation and interaction in the asynchronous discussion forum among K-12 participants, an international community is established to encourage international friendship.

Table 1. Project-based learning in ACA's Networked Collaborative Learning Program

\begin{tabular}{ll}
\hline $\begin{array}{c}\text { Networked } \\
\text { Collaborative } \\
\text { Learning Program }\end{array}$ & \multicolumn{1}{c}{ Objectives } \\
\hline Convenience store & $\begin{array}{l}\text { Understand the } \\
\text { cultural differences of } \\
\text { convenience stores in } \\
\text { different countries and } \\
\text { currency conversion }\end{array}$ \\
Our holidays & $\begin{array}{l}\text { Compare and } \\
\text { contrast holidays in } \\
\text { different countries } \\
\text { through cross-group } \\
\text { collaboration }\end{array}$ \\
Money & $\begin{array}{l}\text { Understand monetary } \\
\text { systems and discuss }\end{array}$ \\
& $\begin{array}{l}\text { the value of money } \\
\text { in APEC member } \\
\text { economies }\end{array}$ \\
& $\begin{array}{l}\text { Enrich cultural } \\
\text { diversity through the } \\
\text { exchange of schooling } \\
\text { experiences in different } \\
\text { school }\end{array}$ \\
& countries
\end{tabular}

The 2006 ACA contest attracted 132 teams from 8 APEC countries as listed in Table 2 below.
Table 2. Number of teams participating in the 2006 ACA contest

\begin{tabular}{cccc}
\hline Country & $\begin{array}{c}\text { Number of } \\
\text { Teams }\end{array}$ & Country & $\begin{array}{c}\text { Number } \\
\text { of Teams }\end{array}$ \\
\hline Taiwan & 66 & Thailand & 5 \\
Philippines & 29 & Japan & 4 \\
USA & 19 & Korea & 1 \\
Indonesia & 7 & Malaysia & 1 \\
\hline
\end{tabular}

\section{Research Questions}

This study examined the attitudes of middle-school students toward networked collaborative learning activities and the various factors contributing to the utilization of ICT. The research addressed the following questions:

1. Do student perceptions toward ICT and project-based learning activities change after completing ACA activities?

2. What motivates students to use technology to complete projects?

\section{Methods}

\subsection{Design}

This study utilized action research, an approach in which the main goal is to improve educational practice in a specific setting (Fraenkel \& Wallen, 2006). Action research is a process that involves all participants (e.g., students, teachers, and other parties) as they collaborate to improve instruction and curriculum. Social psychologist Kurt Lewin's work (1946) has contributed greatly to the maturation of action research as a method for research. According to Lewin's (1946) definition, "action research is a three-step spiral process of (1) planning which involves reconnaissance; (2) taking action; and (3) fact- 
finding about the results of the action" (p. 27, cited in Kemmis, 1988). Action research is an ideal tool for generating insightful information about the improvement of school programs. The method provides educators with opportunities to systematically evaluate ideas about teaching, curriculum, and learning within authentic contexts, so that they can make informed decisions about change.

This action research project consisted of three stages: (1) an initial review of student knowledge and skills in ICT and Asian culture; (2) project implementation; and (3) project evaluation and revision. Data collected includes surveys (students completed a Web-based survey (Appendix I) on perceptions toward ICT skills and subject matter at the beginning and end of the project.), observation logs by the in-class facilitators, and one-on-one student interviews. The main researcher, who was one of the facilitators in the classroom, was not the classroom instructor and did not provide direct instruction to the students. The main role of the researcher was to observe student participation and collect research data.

\subsection{Participants}

A total of 36 middle school students $\left(7^{\text {th }}\right.$ and $8^{\text {th }}$ grade; 22 female, 14 male; $61.1 \%$ Black, 30.6\% White, 5.6\% Asian, and 2.8\% Hispanic) in two technology-enrichment classes participated in the project. The students were enrolled in the Inter-District Downtown School, a K-12 school with 484 students (2005-2006 school year) in downtown Minneapolis, Minnesota, USA. The population's demographic composition is $62 \%$ African American or African, 30\% Caucasian, 3\% Hispanic, 3\% Asian, and $1 \%$ American Indian. $55 \%$ of all students qualify for free and reduced lunch. Students were divided into eight teams of four to six members and registered for the Networked
Collaborated Learning Program (NCLP; see Table 2) in ACA. They spent an average of 2.5 hours/week for a total of nine weeks in a Windows-based computer lab to work on their projects.

\subsection{Instruments}

The student survey was adopted from the Young Children's Computer Inventory (YCCI) by Miyashita \& Knezek (1992). The YCCI was tested with Japanese, Mexican, and American students with high validity and reliability. The original survey examined children's attitudes in the following six areas: computer importance (I), computer enjoyment (J), motivation/ persistence (M), study habits (S), empathy (E), and creative tendencies (C). The student survey (see Appendix I) for this study was developed with questions that focused on computer importance, enjoyment, and other specific ACA areas. The survey instrument had a reliability of .726 using Cronbach's Alpha.

\subsection{Data Collection}

Qualitative and quantitative data were collected. Quantitative data were collected from the Web-based pre-test and post-test (Appendix I). Students completed Web-based surveys during the first week and the last week of the contest. The data were then imported into SPSS for statistical analysis. Qualitative data were collected from student interviews, observers' log journals, and the researchers' meeting minutes. Student interviews were recorded with a MP3 recorder and transcribed by a professional transcriber who was not a member of the research team. The transcripts were reviewed by the student participants to ensure accuracy. The observers kept a weekly journal that served as the field notes on observable behaviors that engaged students in project completion. The research team also met several times during and after the ACA contest 
to discuss the progress of the student projects. The meeting minutes were used for qualitative analysis. This study collected data from multiple sources of evidence to minimize research bias. All research team members reviewed the data and results to ensure fairness in the analysis.

\section{Data Analysis, Results, and Discussion}

\subsection{Student perceptions toward ICT and ACA activities}

Prior to joining the ACA activities, students took a pre-test to rate their own computer skills and knowledge about countries, holidays, and currencies in Asia. At the end of the ACA contest, they took a post-test. The survey questions used a Likert-type scale ranging from 1 to 5 , with 1 being "strongly disagree" and 5 "strongly agree". The survey could be divided into four parts: (1) attitudes toward computer and online communication, (2) self-evaluated skills in information and communication technology (ICT), (3) knowledge about ACA content, and (4) use of email, the Internet, and computers. A paired-sample t-test was used to compare pre and post-test differences in the attitudes and perceived skill improvements as indicated in Table 3.

There was no significant difference in attitudes toward computer activities between

Table 3. Paired sample t-test of pre and post-test of perceptions toward computers and selfevaluated ICT skills $(\mathrm{N}=36)$

\begin{tabular}{|c|c|c|c|c|}
\hline \multirow{2}{*}{ Questions } & \multicolumn{2}{|c|}{ Pre-Test } & \multicolumn{2}{|c|}{ Post-Test } \\
\hline & & $S D$ & $M$ & $S D$ \\
\hline \multicolumn{5}{|l|}{ I. Attitudes toward computer activities } \\
\hline 1. I enjoy online chatting. & 4.31 & 0.87 & 4.22 & 0.77 \\
\hline 2. I enjoy doing things on a computer. & 4.49 & 0.66 & 4.53 & 0.61 \\
\hline 3. I enjoy computer games very much. & 3.94 & 0.84 & 4.06 & 1.03 \\
\hline 4. I can learn many things when I use a computer. & 4.00 & 0.77 & 4.17 & 0.85 \\
\hline \multicolumn{5}{|l|}{ II. ICT Skills } \\
\hline 5. I know how to write a Web page. & 2.69 & 1.18 & 3.72 & $1.16^{* *}$ \\
\hline 6. I know how to use a digital camera. & 3.83 & 1.23 & 4.29 & $0.86^{*}$ \\
\hline 7. I know how to create a digital video. & 2.83 & 1.11 & 3.66 & $1.24 * *$ \\
\hline $\begin{array}{l}\text { 8. I feel comfortable communicating with other } \\
\text { students online. }\end{array}$ & 3.86 & 0.88 & 3.89 & 0.71 \\
\hline $\begin{array}{l}\text { 9. I feel comfortable communicating with other } \\
\text { students face-to-face. }\end{array}$ & 3.83 & 0.61 & 4.17 & $0.70^{*}$ \\
\hline
\end{tabular}

Note: 1: Strongly Disagree, 2: Disagree, 3: Slightly Agree, 4: Agree, 5: Strongly Agree 
the pre and post-test. Student interest and attitudes toward computer activities such as online chatting, computer games, and working on computers remained strong throughout the nine weeks of activities. The second part of the survey on ICT skills demonstrates statistically significant student improvement in Web editing, digital camera use, and digital video creation (as shown in Table 3). Interestingly, students also showed an increased positive attitude toward face-to-face communication as a result of the ACA activities. Students worked in teams to complete projects for nine weeks, and thus, had more opportunities to communicate with teammates in person.

Data for the third part of the survey on content showed some improvement in knowledge in terms of country names and holidays. The three main themes in the ACA contest were to increase student knowledge about Asian countries, currencies, and holidays. Students were asked to write down as many names of countries, currencies, and holidays in Asia as possible. Students remembered more country names on the post test $(\mathrm{M}=6.2)$ than on the pre-test $(\mathrm{M}=4.6)$, which is a statistically significant increase, $\mathrm{t}(34)=-2.17, \quad \mathrm{p}<.05$. Students did not show a statistically significant increase in knowledge of currency or holidays names. This may be due to the lack of specific tasks that teach this particular knowledge of Asian countries.

For the fourth part of the survey on usage, the data indicated that the majority of students increased the use of Internet and publiclyhosted Web sites such as MySpace (61.1\%), email (91.7\%), and a home computer (94.4\%) at the end of the ACA activities (see Table 4). This could be due to the fact that during the ACA activities, students were active in sharing each other's homepages and sharing information through email. Students who have restricted access to computers at home, would ask the instructor to notify their parents about their technology needs to continue working on projects at home.

Table 4. Percentage of students who utilize Web sitse, Email, and computers outside classroom

\begin{tabular}{lcc}
\hline \multicolumn{1}{c}{ Access } & Pre-test & Post-test \\
\hline $\begin{array}{l}\text { Thave my own } \\
\text { Web site through a } \\
\text { public space such as }\end{array}$ & $52.8 \%$ & $61.1 \%$ \\
$\begin{array}{l}\text { MySpace. } \\
\begin{array}{l}\text { I have my own email } \\
\text { account. }\end{array}\end{array}$ & $77.8 \%$ & $91.7 \%$ \\
$\begin{array}{l}\text { I have a computer at } \\
\text { home. }\end{array}$ & $91.7 \%$ & $94.4 \%$ \\
\hline
\end{tabular}

The survey data indicated an overall improvement in interest toward networked learning, knowledge in Asia, and skills inWeb design. This is supported by the claim of Kreijins, Kirschner, Jochems, and Buuren (2007) that a sociable computer-supported collaborative learning environment can fulfill the learning and social needs of students. Students in this study showed strong interest in interacting with members of the community and demonstrated improvement in knowledge and skills.

\subsection{Student Motivation}

To answer the second research question, we collected data from open-ended questions in the surveys and individual interviews with students. In order to learn more about what motivates or discourages students to use technology, one-on-one interviews were conducted with eight students with different levels of web editing skills. Web skill levels were used as the selection criteria because students were asked to assess their Web skill level in the survey. Web skills are also essential in the completion of ACA projects. 
The classroom teacher concurred with students' self-assessment of their Web skills. Two students had low level skills, three students were at an intermediate level, and three students considered themselves highly skilled. The following questions were asked:

1. What are the subjects that you like at school?

2. What kind of activities do you like to do on a computer?

3. What part of ACA activities do you like best?

4. What part of ACA activities do you like least?

5. Have you gained any content knowledge or made any friends via ACA activities?

6. What computer activities would you like to work on in the future?

Student interviews were digitally recorded with a MP3 recorder and then transcribed. Several themes emerged from the analysis of the open-ended survey questions and interview transcripts.

\subsubsection{General attitudes toward school and} computers. The majority of students expressed an interest in improving their computer skills through the ACA projects. All interviewees also indicated interest in at least one or two subjects at school. Their favorite computer activity was updating their information in MySpace, regardless of their skill level.. One student mentioned that she would update her own site every day. If there was nothing to write, she would just change the font size, color, or background on the Web pages. Using the Web as a means to communicate with friends has become an essential part in the daily life of many of today's teens.

6.2.2. Favorite activities in $A C A$. The majority of students indicated that chatting with classmates or friends they made in ACA was their favorite activity. Their second favorite activity was to make a Web page about themselves. Some students indicated that they enjoyed learning about different cultures from the projects shared by other teams. The findings were consistent among students of all skill levels. One student added that "I like doing it on the APEC Web site just because my parents know that it's safe and it's fun because I get to talk to people from around the world."

6.2.3. Limitations of $\boldsymbol{A C A}$. Students pointed out several constraints in being able to complete their ACA projects. Their responses can be grouped into the following categories: (1) insufficient time to complete all tasks; (2) topics not interesting enough; (3) glitches in the system such as not being able to enable the chat function at times; (4) unfriendly feedback on projects from other team members, (5) lack of necessary resources such as a digital camera; (6) content not relevant to the school's curriculum, (7) lack of organization at the beginning; and (8) complicated upload process.

6.2.4. Areas of knowledge and skill gain. Most students indicated that they learned something about different countries and became better in Web page design. They learned to name more countries in Asia, but when asked what specific aspects of Asian culture they had learned about, most students could not provide specific examples. Nevertheless, students felt that they learned something. Most importantly, the content learning depended on what projects students were assigned to or evaluated. There was a lack of specific benchmarks for content learning, such as knowing at least 10 capitals and countries in APEC countries, which could be provided in the future. One student suggested a weekly self-test to help students monitor their own progress. 
6.2.5. Suggested computer activities. A few students were not very engaged in any of the activities. One student contended that "Some kids like using the computer but they're just not interested in learning about the Asian culture. Some of the kids weren't interested at all. They didn't want to do it at all. That's one problem." Students suggested activities that are tied to their own interests such as rap music or computer games would make the ACA project more interesting. One student who showed very little interest in working on the ACA project indicated that he would be happy to do a comparative study on rap music in the USA and China, so that he could work on an engaging subject and learn something about other countries at the same time. Students who showed little improvement in Web skills all stressed the importance of choosing a relevant topic to work with. Students indicated that it would be more interesting if they had their choice of topic.

The interview data results are supported by the motivation statement of Gambrell and Morrow (1996) that freedom of choice is linked to motivation in the classroom. Students reflected that they would put forward more effort when more project choices were allowed and the opportunities to interact with members of community increased. In short, to maintain student motivation in the learning process, it is important to provide engaging content for students, ensure smooth access to the network and equipment, provide structure, supervision, clear instructions and tools for self-monitoring, and most of all, increase project relevancy to match real-life experiences and interests.

\subsection{Strategies for project improvement}

Through the analysis of the observation log journals, researchers' meeting minutes, and the instructor's suggestion, we have proposed the following instructional strategies to better engage the students. The following guidelines are suggested based on the above mentioned qualitative data for successful implementation of the ACA projects with American students in a diverse environment:

- Encourage more communication with others for learning purposes: Because most of the students do enjoy chatting, they could be asked to interview students from other countries to gather information that can help them complete their own projects. For example, when a team is assigned to create a project on Christmas, they would need to research if and how other countries celebrate Christmas. Instead of doing a Google search, they could email other teams or post a question on the discussion forum to inquire how other countries celebrates a specific holiday.

- Make the ACA project more relevant to students' lives: Some students found it difficult to work on certain projects that were not relevant to them, for example a holiday that was celebrated by another country. One team took it upon themselves to add Christmas to their holiday projects after completing the assigned topic on a Russian holiday because it was three weeks before Christmas. Making learning tasks more relevant for students will aid in increasing knowledge gained and skill development.

- Assign specific tasks to each team member to ensure collaboration: While a certain degree of freedom in project work is important, students need structure and purpose. In our projects, students were assigned to play one of four roles in each team: reporter, researcher, photographer, and Web designer. However, this was not enough. Each person could also work on a Web page based on the 
role that they were assigned to. For example, the photographer could work on a Photo Gallery page that includes all pictures taken or collected from the Internet. This should be accompanied by a mechanism to keep each person accountable for their tasks so it was very easy for the individual to slip away from their assigned role or not do their job at all. As one student commented, "I think the most fun time that I had was being assigned to do things because then I know what I'm supposed to do." A rubric to evaluate the individual role by the teammates could be one way to keep each person accountable for their tasks.

- Allow multi-tasking: Students usually had search engines, the ACA Web site, a Web editor, and music on at the same time. Some were able to concentrate better when they worked on multiple projects and with music in the headsets. Students with short attention spans or too much energy became less of a disturbance to other students when they were allowed to use their headsets to listen to music. We noticed a climate change in the classroom when the music was on and students tended to be more engaged in projects.

\section{Limitation of Study}

This study had one major limitation. There was not sufficient time to incorporate improved strategies with the same group of students for the same contest. After the students have completed the contest, they moved on to the next grade level. The ACA organizer also decided to use 2007 to redesign the project content. No contest took place in 2007. It was not possible to evaluate if the revised instructional strategies would better motivate students. It would be ideal to implement the improved strategies with the same group of students to observe the results. The research team did incorporate the strategies in the 2008 contest and the data will be analyzed for future publication.

\section{Conclusion}

The main objective of this research was to investigate ways to engage middle school students in learning with technology. To engage students in project-based learning in a networked environment, they need to be coached in collaboration skills, given appropriate roles to ensure proper division of labor, and supervised closely to ensure the completion of tasks. In a networked environment such as ACA that emphasizes a learner-constructed knowledge base and peer learning, it is important to provide students with clear guidelines and specific tasks to complete. Otherwise, they could easily spend hours mindlessly browsing through the Internet without accomplishing much. To get the students to work on a computer is the easy part. To keep them interested and help them achieve their learning objectives requires thoughtful planning.

The findings of this study showed that students enjoy networked-based learning and communication with peers. In the ACA project, students were very interested in utilizing ICT tools to share information with students from other countries. They also demonstrated a great interest in creating Web pages that were relevant to their worlds. It is especially these affordances of ICT and the needs for social interaction of the N-Geners that should be exploited by educators to achieve desirable learning outcomes.

Too often, educators attempt to integrate ICT in ways that are seen as irrelevant or useless by students, because they attempt to fit innovative tools into conventional classrooms and traditional pedagogy. They are not able 
to communicate with digital natives in ways that are familiar to them (Prensky, 2001). Consequently, students often feel a disconnect between what they learn in school and what they do in their daily lives.

K-12 education will be in peril if and when educators cannot keep their students engaged. ICT is not a solution for all, but could be one way to reach students. During this study, we witnessed the potential power of ICT and the transformation of some students from disengaged to eager learners. However, we also observed the disengagement of some students due to a lack of relevant topics. Therefore, our research is another example of the need to combine ICT with a well-thought out curriculum in order for learning to occur.

The APEC Cyber Academy will continue to make improvements in learning modules, scaffolds, and supporting ICT tools, based on the findings from research such as what has been reported here. Future research will focus on improving access to ACA learning modules, better integration of networked learning in K-12 education, encouraging more and more substantial communication between students from different countries, and increasing student engagement.

\section{References}

Au, K. H. (2006). Diversity, technology, and the literacy achievement gap. In M. C. McKenna, L. D. Labbo, R. D. Kieffer \& D. Reinking (Eds.), International handbook of literacy and technology (volume II) (pp. 363-367). Mahwah, NJ: Lawrence Erlbaum Associates.

Collis, B. A. (1994). Collaborative learning and CSCW: Research perspectives for interworked educational environments. In R. Lewis \& P. Mendelsohn (Eds.), Lessons from learning (pp. 81-104). North-Holland:
Elsevier Science B. V.

Fraenkel, J. R., \& Wallen, N. E. (2006). How to design and evaluate research in education (6th ed.). New York: McGraw-Hill Inc.

Gambrell, L. B. (2006). Technology and the engaged literacy learner. In M. C. McKenna, L. D. Labbo, R. D. Kieffer \& D. Reinking (Eds.), International handbook of literacy and technology (volume II) (pp. 289-294). Mahwah, NJ: Lawrence Erlbaum Associates.

Gambrell, L. B., \& Morrow, L. M. (1996). Creating motivating contexts fro literacy learning. In L. Baker, P. Afflerbach \& D. Reinking (Eds.), Developing engaged readers in school and home communities (pp. 115-136). Hillsdale, NJ: Lawrence Erlbaum Associates.

Gunawardena, C. N., \& Zittle, F. (1997). Social presence as a predictor of satisfaction within a computer mediated conferencing environment. American Journal of Distance Education, 11(3), 8-25.

Henri, F., \& Rigault, C. R. (1996). Collaborative distance learning and computer conferencing. In T. T. Liao (Ed.), Advanced educational technology: research issues and future potential (Vol. 145, pp. 45-76). Berlin: Springer.

Jenlink, P., \& Carr, A.A. (1996, JanuaryFebruary). Conversation as a medium for change in education. Educational Technology, 31-38.

Kaye, A. R. (Ed.). (1992). Collaborative learning through computer conferencing (Vol. 190). Berlin: Springer-Verlag.

Kemmis, S. (1988). Action research in retrospect and prospect. In S. Kemmis \& R. McTaggart (Eds.), The action research planner (3rd ed.). Victoria, Australia: Deakin University.

Kreijns, K., Kirschner, P. A., Jochems, W., \& Buuren, H. v. (2007). Measuring perceived sociability of computer-supported collaborative learning environments. 
Computers \& Education, 49, 176-192.

Lenhart, A., Madden, M., Macgill, A. R., \& Smith, A. (2007). Teens and social media: The use of social media gains a greater foothold in teen life as they embrace the conversational nature of interactive online media: Pew Internet \& American Life Project.

Lewin, K. (1946). Action research and minority problems. Journal of Social Issues, 2(4), 34-46.

Lin, C.-S., Chou, C. C., \& Bagley, C. (2007). Chapter IX: APEC cyber academy: Integration of pedagogical and $\mathrm{HCI}$ principles in an international networked learning environment. In E. McKay (Ed.), Enhancing learning through human computer interaction (pp. 152-175). Hershey, PA: Idea Group Inc.

Miyashita, K., \& Knezek, G. (1992). The young children's computer inventory: ALikert scale for assessing attitudes related to computers in instruction. Journal of Computing in Childhood Education, 3, 63-72.

Pea, R. D. (1993). Practices of distributed intelligence and design for education. In G. Salomon (Ed.), Distributed cognition: Psychological and educational considerations (pp. 47-87). Cambridge, England: Cambridge University Press.

Prensky, M. (2001). Digital natives, digital immigrants. Retrieved August 1, 2007, fromhttp://www.marcprensky.com/writing/ Prensky\%20-\%20Digital\%20Natives, \%20 Digital\%20Immigrants\%20-\%20Part1.pdf

Scardamalia, M., \& Bereiter, C. (1996). Adaptation and understanding: A case for new cultures of schooling. In S. Vosniadou, E. D. Corte, R. Glaser \& H. Mandl (Eds.), International perspectives on the design of technology-supported learning environments (pp. 149-163). Mahwah, NJ: Lawrence Erlbaum Associates.

Schiefele, U. (1991). Interest, learning, and motivation. Educational Psychologist 26,
299-323.

Sandholtz, J., Ringstaff, Cathy, and Dwyer, David C. (1997). Teaching with technology: Creating student centered classrooms. New York: Teachers College Press.

Tapscott, D. (1999). Growing up digital: The rise of the net generation. New York: McGraw Hill.

Teen Research Unlimited (1999). Teen Marketing and Lifestyle Study, Wave 34. NorthBrook, IL.

Valdez, G., McNabb, M., Foertsch, M., Anderson, M., Hawkes, M., \& Raack., L. (2001). Computer-based technology and learning: Evolving uses and expectations. Retrieved December 18, 2006, from www. tc.umn.edu/ $\sim \mathrm{mcleod} /$ criticalissues/pdf/ valdez.pdf

Verdejo, M. F. (1996). Interaction and collaboration in distance learning through computer mediated technologies. In $\mathrm{T}$. T. Liao (Ed.), Advanced educational technology: Research issues and future potential (pp. 77-88). Berlin: Springer. 


\section{APPENDIX I: ICT and Content Knowledge Survey}

\section{Dear IDDS Students,}

Thank you for attending the APEC Cyber Academy annual contest. We would like to assess your skills in computer and communication technology. Please complete the survey.

Thanks,

ACA Project Team

$1=$ Strongly disagree; 2 = Disagree; 3 = No Opinion; 4 = Agree; and $5=$ Strongly Agree $($ N.A. $=$ non-applicable)

\section{Name:}

\begin{tabular}{|c|c|c|c|c|c|}
\hline Questions & 1 & 2 & 4 & 5 & N.A. \\
\hline \multicolumn{6}{|l|}{ 1. I enjoy online chatting. } \\
\hline \multicolumn{6}{|l|}{ 2. I enjoy doing things on a computer. } \\
\hline \multicolumn{6}{|l|}{ 3. I enjoy computer games very much. } \\
\hline \multicolumn{6}{|l|}{ 4. I can learn many things when I use a computer. } \\
\hline \multicolumn{6}{|l|}{ 5. I know how to write a Web page. } \\
\hline \multicolumn{6}{|l|}{ 6. I know how to use a digital camera. } \\
\hline \multicolumn{6}{|l|}{ 7. I know how to create a digital video. } \\
\hline \multicolumn{6}{|l|}{$\begin{array}{l}\text { 8. I feel comfortable communicating with other students } \\
\text { online. }\end{array}$} \\
\hline \multicolumn{6}{|l|}{$\begin{array}{l}\text { 9. I feel comfortable communicating with other students } \\
\text { face-to-face. }\end{array}$} \\
\hline \multicolumn{6}{|l|}{ 10. I know at least three different countries in Asia. } \\
\hline \multicolumn{6}{|l|}{ 11. Write down all the countries in Asia that you know } \\
\hline \multicolumn{6}{|l|}{ 12. I know at least three different currency names in Asia } \\
\hline \multicolumn{6}{|l|}{ 13. Write down all the currency names you know in Asia. } \\
\hline \multicolumn{6}{|l|}{ 14. I know at least three different holidays in Asia } \\
\hline \multicolumn{6}{|l|}{ 15. Write down all the holidays you know in Asia } \\
\hline $\begin{array}{l}\text { 16. I have my own web site through a public space such as } \\
\text { my space. }\end{array}$ & \multicolumn{5}{|c|}{ Yes No } \\
\hline 17. I have my own email account & \multicolumn{5}{|c|}{ Yes No } \\
\hline 18. I have a computer at home. & \multicolumn{5}{|c|}{ Yes No } \\
\hline 19. I have friends in Asia. & \multicolumn{5}{|c|}{ Yes No } \\
\hline \multicolumn{6}{|l|}{ 20. List you favorite activities in ACA. } \\
\hline 21. Comments on activities & & & & & \\
\hline
\end{tabular}




\section{Contact the Authors}

\section{Candace Chou, Ph.D.}

University of St. Thomas

Email: ccchou@stthomas.edu

\section{Chi-Syan Lin, Ph.D.}

National University of Tainan

Email: linc@mail.nutn.edu.tw

Mark van't Hooft, Ph.D.

Kent State University

Email: mvanthoo@kent.edu

Yi-Mei Lin, Ph.D.

National Chung Cheng University

Email: telyml@ccu.edu.tw 